\title{
zumbi nas telas: breve história de uma metáfora
}

Fernando S. Vugman'

I Fernando S. Vugman é doutor em literaturas da Língua Inglesa. Professor do Programa de Pós Graduação em Ciências da Linguagem da UNISUL. Editor da Revista Crítica Cultural. Autor de A casa sem fim (contos) e Ficção e pesadelos (pós)modernos. E-mail: fernando.vugman@unisul.br 
ano 2 número 4

Temáticas

Livres

\section{Resumo}

Breve relato histórico dos filmes de zumbi produzidos nos Estados Unidos, comentando alguns dos mais significativos, como Zumbi branco (1932), dirigido por Victor Halpering e estrelado por Bela Lugosi, e que inaugura o gênero. Outros filmes a merecerem comentário são A morta viva (1943), de Jacques Tourner, ainda na fase "haitiana"; A noite dos mortos vivos (1968), dirigido por George Romero, filme que inaugura uma nova fase do gênero; além de Zumbilândia (2009) do diretor Ruben Fleischer, e Meu namorado é um zumbi (2013), de Johnatan Levine. Especial atenção é dada às funções metafóricas do zumbi.

\section{Palavras-chave}

Zumbi. George Romero. metáfora. Hollywood.

\section{Abstract}

Brief historical review of zombie films produced in the US, with comments on some of the most relevant ones, as White Zombie (1932), by Victor Halpering and starred by Bela Lugosi, which inaugurates the genre. Other commented films are I Walked with a Zombie (1943), by director Jacques Tourner, still in the "Haitian" phase; Night of the Living Dead (1968), by George Romero, the film that begins a new phase in the genre; and also Zombieland (2009), by Fleischer; and finally Warm Bodies (2013), by Johnatan Levine. Especial attention is devoted to the metaphorical functions of the zombie.

\section{Keywords}

Zombie, George Romero, metaphor, Hollywood. 
Dentre os monstros que tem povoado as telas de cinema, o zumbi exibe algumas particularidades. Diferentemente de monstros como Drácula e a criatura do Dr. Frankenstein, personagens oriundos da literatura e, portanto, desde cedo merecedores de atenção da crítica, o zumbi emergiu, segundo Peter Dendle, "nos anos 1930 como um monstro cinemático ajustado de forma única para se dirigir a muitas das tensões sociais da América do período da Grande Depressão" (2007, P. 46. Tradução nossa)². De fato, e assim argumentaremos neste texto, o zumbi tem se apresentado como figura particularmente útil para expressar as mais variadas angústias e tensões culturais, especialmente a partir de A noite dos mortos vivos (Romero, 1968).

A figura do monstro tem aparecido em todas as culturas ao longo da história como símbolo de todo o Mal. Nestas narrativas, o monstro é criado no interior da própria sociedade que deseja sua destruição; entretanto, filho daquela sociedade, seu impulso é sempre o de buscar sua aceitação e integração social. Seu movimento neste sentido, porém, conduz à relativização do código moral daquela sociedade, que deseja sua destruição ou expulsão definitiva, como forma de recuperar a estabilidade do seu código de valores. Como no "mundo real" não existe a possibilidade de se eliminar todo o mal (a começar por sua sempre instável e fugidia definição), no plano simbólico destas narrativas permanece sempre aberta a promessa do retorno do monstro, seja por um descendente direto, por um novo monstro, ou por ele mesmo, numa eterna ressurreição.

Como todo monstro, o zumbi tem o potencial de apagar as fronteiras entre o Bem e o Mal. Ou, na expressão empregada por Dendle, o zumbi traz à tona as "tensões culturais" de uma sociedade. Para nosso interesse aqui, o zumbi aparece como metáfora de potencial riquíssimo daquilo que a sociedade estadunidense tem considerado, ao longo da história recente, como o Mal (e os males) que a aflige. Assim, enquanto traçamos um breve

2. "(I)n the 1930 s as a cinematic monster uniquely suited to address many of the social tensions of Depression-era America”. 
ano 2 número 4

Temáticas

Livres

quadro histórico deste subgênero do horror, desde sua or igem até Meu namorado é um zumbi (2013), de Johnatan Levine, iremos apresentar algumas de suas funções metafóricas nos filmes do zumbi "haitiano" e argumentar que a partir de George Romero seu potencial metafórico se amplia enormemente.

Desde Zumbi branco (1932), dirigido por Victor Halpering e estrelado por Bela Lugosi, a figura do zumbi frequenta os filmes hollywoodianos. Surgindo dentro das convenções do estilo "hor ror", onde encontramos o elemento sobrenatural, ou inexplicável, o castelo terrível, num precipício à beira do mar, a heroína ingênua dominada pelo vilão, a atmosfera de mistério e suspense e o herói enlouquecido pela pressão de uma situação incompreensível ${ }^{3}$, Zumbi branco estabelece as primeiras convenções específicas: o morto vivo como um ser escravizado por um senhor por meio da magia ou da feitiçaria (sugerindo a alienação espiritual do trabalhador em relação ao seu trabalho, bem como o impedimento do usufruto dos bens que produz); como ser sem vontade própria e insensível à dor; o figurino pobre, que remete ao figurino do monstro cinemático de Frankenstein (frequentemente lido como metáfora do trabalhador explorado no início da era industrial), mas também referente aos trabalhadores explorados nas colônias europeias; e a divisão dos personagens basicamente entre uma aristocracia ociosa e trabalhadores sem direitos, explorados no campo ou em uma estrutura fabril muito primitiva.

Resumidamente, é a história de um jovem casal apaixonado, Neil (John Harron) e Madeleine (Madge Bellamy), que aceita o convite de Beaumont (Robert Frazer), um homem que conhecem numa viagem de trem, para visitar sua mansão no Haiti, e ali realizarem sua cerimônia de casamento. Na verdade, Beaumont apaixonou-se por Madeleine e pediu ajuda a Murder Legendre (Bela Lugosi) para conquistá-la durante a visita. Legendre é um feiticeiro que revive mortos para submeter seus inimigos e para obter mão de obra escrava.

Usando um cachecol de Madeleine, Legendre faz um feitiço vodu, matando-a e trazendo-a de volta dos mortos para se entregar a Beaumont. Entretanto, 
Beaumont logo percebe que não pode se satisfazer com uma mulher zumbi, sem alma, sem vontade e sem desejo, e se arrepende. Enquanto isto, Neil, o noivo, entra em profunda depressão após o enterro da amada e mergulha na bebida. Quando descobre que Madeleine se tornou uma morta-viva, segue até o castelo de Legendre para se vingar e salvar a noiva.

Vale ressaltar outros elementos do filme que ajudam a estabelecer um contexto entre o pré-moderno e pré-industrial e a sociedade industrial em formação: $O$ casal protagonista, apesar da menção à modernidade nova-iorquina, chega à mansão de Beaumont à noite, numa carruagem, por uma sombria estradinha de terra (uma sequência muito semelhante àquela da chegada de Jonathan Harker ao castelo do Conde Drácula, tantas vezes encenada por Hollywood). Em um determinado ponto do caminho encontram um grupo de homens e mulheres vestidos como trabalhadores do campo, elas com lenços na cabeça e eles de chapéu de palha, enterrando um morto em pleno leito da estrada. E os zumbis de Legendre, quase todos negros ou mestiços, trabalham na plantação de cana, ou na fábrica de açúcar, em que o pouco maquinário é movido pelos seus corpos. Assim se estabelecem as convenções da fase clássica deste gênero: indivíduos sem alma e sem vontade própria, despertados da morte por um senhor perverso e cruel, movendo-se num cenário que se alterna entre castelos sombrios ou ricas propriedades rurais e plantações de cana, em meio ao qual acompanhamos uma heroína branca perseguida pelo vilão e salva pelo seu hesitante herói. Enfim, o filme de Halpering dá origem ao que viria a ser convencionalmente chamado de “zumbi haitiano", que perdurará até o aparecimento do zumbi de George Romero.

Onze anos mais tarde, o diretor Jacques Tourner lança A morta-viva (1943), mais uma vez combinando as plantações caribenhas, o vodu e uma mulher branca transformada em zumbi. Aliás, outro elemento de Zumbi branco que vai se repetir em $A$ morta-viva e outros filmes de zumbi deste período, como Ouanga (1936) ${ }^{4}$, é a preocupação com a "apropriação dos corpos femininos e a aniquilação da mente feminina por captores masculinos" (Dendler, 2001. 
ano 2 número 4

Temáticas

Livres

Tradução nossa) $)^{5}$, embora a figura feminina venha a conquistar uma variedade de papéis e funções nos filmes de zumbi a partir de $A$ noite dos mortos-vivos ${ }^{6}$. Também como em Zumbi branco, o filme de Tourner faz seguidas referências à escravidão. Em diferentes momentos da trama personagens se referem lugubremente a uma escultura em madeira de São Sebastião atravessado por flechas no jardim da propriedade, explicando que aquela era a figura de proa do navio negreiro que havia trazido os escravos da família Holland.

Aqui, a história apresenta Betsy (Frances Dee), uma jovem enfermeira canadense que vai às Índias Ocidentais para tratar da Jessica Holland (Christine Gordon), esposa de Paul Holland (Tom Conway), dono de uma fazenda de cana de açúcar. Jessica parece sofrer de um tipo de paralisia mental surgida depois de um episódio de febre. Segundo o médico da família, doutor Maxwell (James Bell), a febre teria danificado a medula espinhal, deixando a paciente sem a capacidade de fazer nada por vontade própria. Os outros membros da família Holland são o meio-irmão Wesley Rand e a Sra. Rand (Edith Barret), médica e mãe de Paul e Wesley.

Logo, Betsy se apaixona por Paul e num gesto extremamente romântico e altruísta decide fazer todo o possível para curar sua esposa, acreditando que ele ainda a ama. Depois do fracasso de um tratamento médico radical conduzido pelo Dr. Maxwell, ela fica sabendo, por meio de Alma (Theresa Harris), empregada da casa, da possibilidade de cura de Jessica através de um ritual vodu, realizado por uma feiticeira da comunidade negra da ilha. Acompanhada de Alma, Betsy leva sua paciente até o centro vodu sem autorização da família. Lá, chocada, descobre que a feiticeira vodu é a própria Sra. Rand, que se justifica dizendo recorrer ao vodu somente para convencer os ilhéus a tomarem seus medicamentos, mas também admite que Jessica jamais poderá ser curada.

A confusão toda envolvendo os nativos e o vodu atrai a atenção da polícia local e, pressionada diante de seus familiares, a Sra. Rand admite ter matado Jessica e a transformado em zumbi, para impedir que ela traísse Paul e fugisse com

5. “(...) appropriation of female bodies, and the annihilation of female minds, by male captors.”

6. Neste ensaio não discutiremos os diferentes papéis femininos nos filmes de zumbi e suas possíveis conotações. 
seu meio-irmão Wesley. Por fim, o próprio Wesley mata Jessica definitivamente, deixando seu corpo para ser encontrado na praia pelos negros da ilha.

A partir da década de 1950, período de intensa produção de filmes de ficção científica como alegorias da Guerra Fria, o zumbi inspirado no vodu e no folclore haitianos começa a exibir uma dispersão das formas de sua caracterização. É quando aparecem zumbis alienígenas, como em Teenage Zombies (James Warren, 1959) e em Invasores invisíveis (Edward L Cahn, 1959); zumbis radioativos, como em Cadáver atômico (Edward L Cahn, 1955); e até zumbis submarinos, a exemplo de O fantasma de Mora Tau (Edward L Cahn, 1957). Entretanto, nestes filmes os zumbis ainda aparecem como personagens bastante secundários. Dentre estes, segundo Cueto, o que mais merece atenção é Invasores invisíveis. De acordo com Cueto:

\begin{abstract}
“(...) esta pequena película B (...) indica que Romero tomou dali algumas das características apresentadas em A noite dos mortos-vivos, tanto do argumento (um grupo de pessoas se encerra num bunker enquanto são cercados por zumbis), como da forma (os mortos, por exemplo, estão caracterizados de forma muito similar)" (2009, p. 58). ${ }^{7}$
\end{abstract}

Mas os filmes de zumbi sofrerão transformações decisivas a partir de $A$ noite dos mortos-vivos. Filmado por George Romero em preto e branco e com baixo orçamento, o filme se concentra num grupo de sete personagens que se isolam numa casa de fazenda abandonada, depois que os mortos começam a sair de suas sepulturas e a vagar por todo o país devorando os vivos. Ali passarão a noite enquanto enfrentam os zumbis do lado de fora e lidam com os conflitos que surgem em meio ao próprio grupo.

Com as novas características atribuídas à figura do zumbi, este personagem se transforma num dos mais populares e bem sucedidos dos subgêneros dos

7. “(...) esta pequeña película B (...) apunta a que Romero tomó de ella algunas de las características de La noche de los muertos viventes, tanto del argumento (un grupo de personas se encierran en um búnker mientras los zombis acosan) como de la forma (los muertos, por ejemplo, están caracterizados de forma muy similar). 
ano 2 número 4

Temáticas

Livres

filmes de terror. Agora, os mortos-vivos não são mais ressuscitados por métodos mágicos, como no vodu; não são mais corpos sem vontade própria e escravizados pelo vilão da trama, mas seres movidos por algum impulso interno e incontível, de origem nunca bem explicada, alheios a qualquer ordem externa. A noite dos mortos-vivos enfatiza a ausência de uma explicação mágica, ou mesmo de qualquer explicação para o aparecimento dos zumbis, e substitui uma vontade regida por um senhor por outra vontade, agora de origem desconhecida, cujo impulso se apresenta como uma fome insaciável pela carne de humanos vivos.

Mais do que isto, Romero cria aquilo que viria a se cristalizar como a "forma zumbi", para dotá-la de um potencial metafórico possivelmente ainda não encontrado em nenhum outro monstro, ou mesmo em qualquer outra figura mitológica. Ao libertá-lo do domínio de um senhor (um feiticeiro, um "cientista maluco", etc.), Romero elimina a relação entre o zumbi e qualquer propósito ou finalidade, mas, ao mesmo tempo, dota-o de uma vontade incontível e sempre agressiva e destruidora. Um ser que se apresenta simultaneamente como uma força da natureza e como um ser sobrenatural. Um ser movido apenas pelo desejo de consumir, mas que nada ganha com este consumo. Uma criatura que se orienta sempre como massa, como multidão. Um monstro cuja aparência é a de alguém que "morreu em vida", ou seja, que se move como os vivos, mas cuja superfície exibe uma destruição mais profunda, interior, uma corrupção da própria alma, da própria vontade. Com tudo isso, não causa espanto que a partir de A noite dos mortos-vivos tenha explodido nas telas filmes de zumbis como metáforas da sociedade de consumo, da sociedade de massas, da preocupação excessiva com a própria aparência e outras angústias relacionadas à aparência das pessoas, das crises de identidade, dos processos desumanizadores da lógica econômica e social contemporânea, do uso pervertido da tecnologia, do medo da morte e de uma variedade aparentemente infindável de instintos e emoções humanas destrutivas latentes.

O filme de Romero também introduz outras novidades significativas. Por exemplo, o cenár io deixa de exibir castelos terríveis e canaviais sombrios e agora os mor tos vivos passam a assombrar a bem cuidada zona rural estadunidense enquanto fora das salas de exibição a sociedade vive os protestos contra a 
guerra do Vietnã, o movimento hippie, a invenção da pílula anticoncepcional e o amor livre, os assassinatos de John Kennedy e de Martin Luther King Jr. e a chegada à Lua. A década de 1960 também pode ser identificada com a chegada definitiva da sociedade estadunidense à modernidade e com a tradução do sonho americano em sonho de consumo. A televisão e o rádio também aparecem como marcas da modernidade.

A noite dos mortos-vivos rendeu grande bilheteria e uma recepção polêmica, pois, além dos aspectos já mencionados, muitos lhe atribuíram uma mensagem antirracista por colocar Duane Jones como o primeiro ator negro a protagonizar um filme de horror. Ben, seu personagem, dotado das qualidades do homem de ação hollywoodiano, é o único que sobrevive ao longo da noite na casa abandonada. Mesmo assim, na manhã seguinte é assassinado com um tiro na cabeça por um dos homens do xerife. Na sequência final vemos fotos de jornal onde seu corpo aparece sendo carregado como o de um morto-vivo.

Desta gama de metáforas potenciais desencadeadas por George Romero, daremos maior atenção, a partir daqui, àquela que o próprio diretor escolheu para desenvolver de modo quase didático nos filmes de zumbi seguintes que realizaria, especialmente em $O$ despertar dos mortos (1978): o zumbi como o individuo desumanizado e dominado pela lógica da sociedade de consumo.

Realmente, dez anos depois, com $O$ despertar dos mortos, Romero faz ainda mais explícita sua crítica ao consumismo ao colocar um shopping center como refúgio dos personagens principais, onde ficam sitiados, pois é para lá que se dirige a massa de zumbis, supostamente movidos pelo imperioso hábito de consumo que os dominava em vida.

Enfim, o zumbi de George Romero passa a simbolizar o individuo típico da sociedade de consumo: o que o move é o desejo irrefreável de consumir, desejo este que se apresenta como um impulso irracional e incontível, que nada acrescenta a sua existência, já que ele está morto. Desprovido de humanidade, ele retém o impulso consumista como último traço do que um dia foi. Movido apenas pelo desejo de consumir, o zumbi nada produz, gerando um desequilíbrio que, levado ao limite, significaria a própria destruição da sociedade humana. 
ano 2 número 4

Temáticas

Livres

Em 2009, com a comédia Zumbilândia, o diretor Ruben Fleischer leva o comportamento dos zumbis consumistas de Romero ao seu limite lógico ao criar uma sociedade onde quase todo mundo no planeta se transformou em mortovivo. Nesta comédia apocalíptica, as pessoas se transformaram em zumbis após consumir hambúrgueres contaminados por um vírus, uma explicação tão vaga e absurda quanto a radiação espacial de A noite dos mortos-vivos. Permanecem como humanos apenas quatro personagens: Columbus (Jesse Eisenberg), um jovem nerd antissocial; Tallahassee (Woody Harreslson), ex-dono de oficina obsecado por encontrar um Twinky (um confeito industrializado) ainda no prazo de validade; e a jovem e sexy Wichita (Emma Stone), e sua irmãzinha adolescente Little Rock (Abigail Breslin).

O filme de Fleischer chega às telas logo depois da eclosão da crise financeira mundial, desencadeada pela quebra do banco Lehman Brothers, nos Estados Unidos, em setembro de 2008. Essa crise, que ainda se arrasta por todo o mundo desenvolvido sem que se aviste seu fim, é resultado justamente de uma lógica econômica e cultural onde na mesma medida em que se abandona a produção e o trabalho, se privilegia o consumo. Uma crise que destruiu a "normalidade" existente e que não permite vislumbrar qualquer nova "normalidade" a ser alcançada.

O cenário de Zumbilândia é um mundo de mercadorias em abundância e sem consumidores (nem os zumbis tem mais quem comer), como os novos pobres que não cessam de surgir nos Estados Unidos e Europa. No filme, o desejo de retorno à antiga normalidade aparece na procura obsessiva de Tallahassee por um Twinky; ao mesmo tempo, a futilidade da antiga normalidade fica bem ilustrada nas várias cenas em que os quatro protagonistas se divertem simplesmente destruindo mercadorias em exposição.

Nos filmes de George Romero sempre há uma volta à normalidade ao final da trama. De um modo ou de outro, seja pelas forças do Estado, seja pela promessa de uma nova sociedade, como em Terra dos mortos (2005), no universo de Romero sempre persiste a esperança de uma normalidade recuperada. O universo de Fleischer não oferece mais essa possibilidade. Quando a lógica do hiperconsumo é levada ao seu limite, onde a relação entre as pessoas é substituída pela relação 
entre os objetos, em que as identidades se constroem baseadas no que se possui, tudo o que resta são pessoas vazias a quem seguir consumindo não serve de mais nada. Sem que se escape desta lógica não há futuro para a sociedade. Do mesmo modo, sem ter para onde voltar, os personagens de Zumbilândia se ocupam cruzando um país vazio e assombrado até atingirem seu objetivo: brincar num grande parque de diversão na costa Oeste. Ao final, alcançado esse objetivo, nada lhes resta. Como consolo, reconhecem-se como uma família. Mas uma família que não tem o que fazer, nem para onde ir. Zumbilândia termina com uma mal disfarçada admissão de que não há mais um futuro.

Entretanto, sempre haverá um futuro. Por mais que a crise mundial siga sem um claro horizonte e sem solução, o mundo segue existindo e as pessoas, vivendo. E é como uma alternativa utópica às distopias de Romero e de Fleischer que aparece, em 2013, Meu namorado é um zumbi, dirigido por Johnatan Levine. Lançado cinco anos depois da eclosão da crise, o filme de Levine situa seus zumbis num mundo pós-apocalíptico semelhante àquele de Zumbilândia, com um punhado de seres humanos lutando para sobreviver num mundo repleto de mercadorias abandonadas e tomado por zumbis.

Se o filme de Fleischer termina sem alternativas para a humanidade, novas transformações no universo de Levine reabrem a possibilidade de um futuro menos estéril; se o primeiro é uma distopia, o segundo é uma utopia. E a utopia do ressurgimento de um mundo reumanizado precisa de um zumbi que fale.

A trama começa com as reflexões de um protagonista incapaz de lembrar o próprio nome, sem memória do passado e... morto. Ele não consegue realmente falar, mas ouvimos seus pensamentos. "R" (Nicholas Hoult), nome que receberá mais adiante da heroína, tem consciência de ser um morto-vivo, e passa a maior parte do tempo perambulando por um aeroporto em meio a uma multidão de outros zumbis. Agora existe um segundo tipo de zumbi, os chamados "esqueletos", em estado mais avançado de decomposição, de feições escuras e sinistras, extremamente agressivos e devoradores de qualquer coisa que tenha um coração pulsante; zumbis que aparentemente perderam seus últimos traços de humanidade. Esses dois tipos de mortos-vivos dominam o planeta. 
ano 2 número 4

Temáticas

Livres

Os humanos que restaram vivem protegidos por altos muros rodeando parte do centro de Nova York. No interior dos muros levam uma vida com poucas esperanças, liderados por uma instituição militar, enviando grupos armados de quando em quando para recolher medicamentos e outras necessidades do lado de fora. E é em uma dessas saídas que Julie (Teresa Palmer) e seu grupo são surpreendidos por zumbis. R mata seu namorado, mas apaixona-se por ela à primeira vista e a salva, conduzindo-a até o avião abandonado que ele habita. Ao longo dos dias que dura essa convivência, segue-se um duplo processo de sensibilização de Julie em relação a R e da própria humanização deste.

Eventualmente, Julie abandona R e retorna para sua casa intramuros, onde seu pai é o comandante militar que odeia zumbis. Desolado, no caminho de volta ao aeroporto, R encontra um grupo de zumbis que, como ele, estão passando por um processo de reumanização. Como ele, começaram a ter sonhos e não mais apenas fragmentos da memória daqueles cujos cérebros comeram. Por conta desse processo de voltar à vida, misteriosamente deflagrado pelo contato entre Julie e R, os “esqueletos” também estão seguindo em direção à cidade sitiada, para dar fim aos humanos e, de quebra, de todos os outros zumbis.

Já dentro da cidadela, R consegue encontrar Julie e juntos tentam, sem sucesso, convencer seu pai (Grigio/John Malkovich) de que os zumbis estão de algum modo se reumanizando. Na confusão que se segue, zumbis e humanos se juntam para enfrentar os esqueletos, derrotando-os. A trama termina com seres humanos e zumbis juntos. Os muros da cidadela são derrubados. Julie e R seguem como namorados. As copas das árvores do Central Park exibem o alaranjado do outono. À plateia é entregue uma vaga utopia, sem uma proposição política mais clara, mas com a promessa de que o amor a tudo vencerá. Finalmente, a sociedade de consumo encontra sua redenção. 


\section{Referências}

ADORNO, Theodor. Indústria cultural e sociedade. São Paulo: Paz e Terra, 2004.

BARTHES, Roland. Mitologias. Rio de Janeiro: Bertrand Brasil, 1993.

CUETO, José Manuel Serrano. Zombie evolution: El libro de los muertos vivientes en el cine. Madrid: T\&B Editores, 2009.

DEBORD, Guy. A sociedade do espetáculo. São Paulo: Contraponto Editora, 1997.

DENDLE, Peter. "The zombie as barometer of cultural anxiety". In SCOTT, Nial. Monsters and the Monstrous: myths and metaphors of enduring Evil. Amsterdan-New York: Editions Rodopi B.V., 2007. 45-56.

DENDLE, Peter. The zombie movie encyclopedia. Jefferson, North Carolina: McFarland \& company Inc., Publishers, 2001.

HARPER, Stephen. "Night of the living dead: reappraising an undead classic". Bright Light Film Journal. Disponível em: http://www.brightlightsfilm.com/50/night.html. Acesso em 19/11/2013.

MORARU, Christian. "Zombie pedagogy: rigor mortis and the U. S. body politic". Studies in popular culture, 34.2 Spring 2012. Disponivel em: http://www.pcasacas.org/SiPC/34.2/Moraru.pdf. Acesso em: 18/11/2013.

PAFFENROTH, Kim; Iona College. "Religious themes of George Romero's zombie movies". Golem Journal. Disponível em: http://www.golemjournal.org/Spinrg_2006_Issue/Paffenroth_ Zombies_S06.pdf. Acesso em 19/11/2013.

SCOTT, Nial. Monsters and the Monstrous: myths and metaphors of enduring Evil. Amsterdan-New York: Editions Rodopi B.V., 2007. 